\title{
What is your discount rate? Experimental evidence of foresters' risk and time preferences
}

\author{
Philipp A. Sauter ${ }^{1}$. Oliver Mußhoff ${ }^{1}$
}

Received: 26 September 2016 / Accepted: 11 December 2017 / Published online: 16 January 2018

(c) INRA and Springer-Verlag France SAS, part of Springer Nature 2018

\begin{abstract}
- Key message The elicited time preference rate of German foresters is around 4.1\%. Foresters working for private enterprises are more risk-averse and have a lower time preference than other foresters. This group difference should be taken into account for modeling and policy making.

- Context Due to very long rotations, forestry investment calculations heavily depend on the underlying discount rate. There is an ongoing debate about the appropriate discount rate to apply in forestry, particularly in light of concerns regarding intergenerational justice, forest risks, and the provision of future positive externalities from forestry. For sound policy making however, knowledge is lacking on the risk and time preferences of foresters.

- Aims The present study aims to provide detailed information about risk and time preferences as essential aspects of the discounting behavior.

- Methods Therefore, we conducted an economic experiment with 142 German foresters. Both risk and time preferences affect discounting behavior, which is why they are estimated jointly but analyzed specifically.

- Results Participating foresters' risk attitudes range between risk-neutral and very risk-averse, where the sample can be mostly characterized as risk-averse. Time preference discount rates range mostly between 0 and $7 \%$, with $4.1 \%$ as a central value. These results are group-specific: foresters working for a private forest enterprise are more risk-averse and have a lower discount rate than other participating foresters.

- Conclusion Foresters' time preferences exceed the usual rates of return in German forestry, which might be explained by additional utility attributed to forest amenity values or the risk-decreasing effects of forest assets in their portfolio.
\end{abstract}

Keywords Time preference $\cdot$ Risk attitude $\cdot$ Foresters $\cdot$ Economic experiment $\cdot$ Maximum likelihood estimation · Policy support

Handling Editor: Rasoul Yousefpour

This article is part of the Topical Collection on Risk Analysis

Electronic supplementary material The online version of this article (https://doi.org/10.1007/s13595-017-0683-5) contains supplementary material, which is available to authorized users.

Philipp A. Sauter

philipp.sauter@agr.uni-goettingen.de

Oliver Mußhoff

oliver.musshoff@agr.uni-goettingen.de

1 Department for Agricultural Economics and Rural Development, Georg-August-Universität Göttingen, Platz der Göttinger Sieben 5, 37073 Göttingen, Germany

\section{Introduction}

Discounting future cash-flows is standard economic practice and has an especially long tradition in forest economics. Due to the long time lapse between planting and harvesting, forest economics is accustomed to dealing with the integration of time in calculations. Thus, forest economics is often regarded as the cradle of dynamic investment appraisals, especially in the context of multiple rotations as with e.g., Faustmann in 1849 (cf. Möhring 2014; Samuelson 1976). Since then, the appropriate discount rate is a matter of intense discussion due to the wide-ranging consequences (Hepburn and Koundouri 2007; Price 2014). For instance, Price (2011) clearly demonstrates the implications 
of various supposed discount rates on net present values as decision criterion. Silviculture costs, in particular, have a great effect on the net present value, since these "frontend-costs" emerge at the very beginning of a rotation. The consequences of using discount rates become obvious in, for example, the choice between allowing natural regeneration versus planting a forest stand. While natural regeneration requires less capital, planting has the advantage of utilizing improved genetics and allowing for more forest planning opportunities (e.g., adaption to climate change and the orientation to fulfill future forest-based needs), which may payoff in the distant future (e.g., Hepburn and Koundouri 2007; Simonsen 2013). This example demonstrates that the determination of the discount rate is of great importance for forest management, as well as forest policy making, since the discount rate has wide-ranging consequences on forest management practices, possibly leading to numerous positive externalities (Hepburn and Koundouri 2007).

In order to determine the 'optimal' discount rate in forestry, a number of studies derived the discount rate from best practice field data or social and environmental opportunity costs, which include, for example, intergenerational justice and positive externalities of forest resources. This exogenously defined discount rate is often referred to as the social discount rate, as described by Kant (1999), Hepburn and Koundouri (2007) and Atmadja and Sills (2013, p. 102).

However, decisions in forestry are made by individuals who do not necessarily follow an exogenously defined presetting. Instead, forestry decision makers are known to be a diverse group, and decisions are mostly based on endogenous individual preferences, where risk and time preferences are important components (Kant 1999, p. 103). There are several studies on the discount rate of foresters, but very few elicited the discount rate of individuals. Bullard and Gunter (2002) as well as Kronrad and de Steiguer (1983) directly asked for the discount rate of foresters by utilizing open-ended questions in a forestry context in the USA. Kronrad and de Steiguer (1983) found a $15 \%$ discount rate for foresters, whereas Bullard and Gunter (2002) investigated different time periods, and found that discount rate ranged from $8 \%$ in a five year rotation to $13 \%$ in a 25 year rotation. Atmadja and Sills (2013, p. 112) used another approach: foresters were given two binomial choice decisions in the forestry context in a mail survey in the USA. They elicited a discount rate of $2.6 \%$ for forest owners with less than 100 acres $(\sim 40$ ha) of land. Prestemon and Wear (2000) estimated individual discount rates from harvesting behavior observed in the USA. They found discount rates of $18 \%$ for non-industrial private forest owners and $2 \%$ for other forest owners.

The observable differences between the elicited discount rates clearly reflect the complexity of the issue. At this point, we want to introduce the differentiation of time discounting and time preference (cf. Frederick et al. 2002). Time discounting involves all reasons why consequences in the future are valued differently than in the present time, while time preference only refers to "the preference for immediate utility over delayed utility" (Frederick et al. 2002, p. 352). With regard to the studies on the elicited discount rate in forestry, time discounting implies that the discount rates are influenced by different individual perspectives and expectations for forest management (Domínguez and Shannon 2011). In addition, it is acknowledged that risk and risk preference are incorporated into the applied discount rate (Anderhub et al. 2001; Frederick et al. 2002). In the forestry context, e.g., Bullard and Gunter (2002) demonstrate that discount rates increase with investment duration, possibly due to the incorporation of the underlying uncertainty, which is in line with the expectations of Samuelson (1976). However, the measurement of discount rates involving risk can lead to misleading estimations, since risk can vary systematically throughout the lifespan of a forest crop. Moreover, keeping in mind the principles of the Faustmann formula, the current risk component in the discount rate not only affects the current rotation, but also the discounting of future rotations (Price 2014, p. 63). Furthermore, the specific influence of risk and time preferences on the measured discount rates differs for each decision maker (Andersen et al. 2008).

Altogether, previously elicited discount rates in the forestry context represent time discounting, which is made up of an unknown conglomeration of factors including, but not limited to, the individual time preference, the individual risk preference, the forest stand risk, and individual associations with forestry investments. As part of a scientific discussion, this is why, e.g., Duquette et al. (2014) prefers the estimation of "pure time preferences" as one component of preferences. ${ }^{1}$ Since time preference as well as risk preference are regarded as key components in inter-temporal decision making (Botzen and van den Bergh 2014), we analyzed them for forestry decision makers on an individual basis. Furthermore, we analyzed how risk and time preferences are connected with socio-demographic and forest-enterprise-related parameters.

\footnotetext{
${ }^{1}$ (Pure) time preference in this article does not refer to an economic target dimension, as discussed by e.g., Price (1993, p. 142, 2014, p. 61-62). Instead, it is regarded as one component of the preferences and influencing parameters with regard to the discounting behavior. Time preference as well as time discounting are measured by the discount rate. In order to distinguish between these discount rates, we explicitly refer to time preference in this case. We assume that foresters do not expect severe changes of income in future times. Otherwise, e.g., higher income expectations in future times imply diminishing marginal utility. Hence, additional income from sources such as savings would be less valued and interest rates needed to be higher to reflect the same time preference as with constant income expectations.
} 
In order to elicit the risk and the time preferences, we conducted an economic experiment involving a risk preference elicitation task and a time preference elicitation task in a neutrally-framed setting. An economic experiment constitutes the appropriate method in this context, since it is the only methodology which can provide evidence on risk and time preferences without influence from uncontrolled external variables, such as those that would be invoked with a forestry-specific framing (cf. Binmore 1999). We used a maximum likelihood approach for estimating risk and time preferences jointly, which allows us to provide evidence of the time preference. For inter-temporal decisions, such as the timing of the harvest or the selection of the planting intensity, the endogenous ${ }^{2}$ time preference can be regarded as an underlying decision foundation (Atmadja and Sills 2013; Kant 1999). In this context, Kant (1999) emphasizes "[...] that sustainable forest management practices should be designed on the basis of the endogenous rate of time preferences of the user group" (Kant 1999, p. 67). This time preference can serve as a basis for sound policy making, where detailed knowledge of decision makers' preferences is a prerequisite (Botzen and van den Bergh 2014). Especially in the forestry context, which involves long crop rotations, detailed knowledge regarding individual time preferences of decision makers is of great importance for effective policy measures, which aim to induce positive externalities from forest management (e.g., Brukas et al. 2001).

Thus, the scientific contribution of this article is twofold. First, to the best of our knowledge, we are the first to elicit risk and time preferences of foresters by utilizing established, neutrally-framed experiments. We thereby contribute to the behavioral analysis of foresters, as recommended by Kant et al. (2013). Second, by estimating risk and time preferences simultaneously, we can provide information not only on the distribution of risk preferences, but also on the distribution of time preferences of foresters. In this way, we contribute to the understanding of foresters' decision making and, thus provide, a fundamental basis for the adjustment of forest management models (e.g., Brukas et al. 2001; Eyvindson and Kangas 2016) and forest policy implication analysis (cf. Anderson and Stafford 2009; Botzen and van den Bergh 2014).

This article is structured as follows: Section 2 describes the experimental design as well as the methodology for the analysis. In Section 3, the resulting experimental data is examined and discussed. Finally, the article is

\footnotetext{
${ }^{2}$ Since forestry decisions are relevant not only over generationspanning time-scales, but also over shorter periods, endogeneity in this study only refers to present decision makers, while intergenerational justice is discussed as a separate component in the Section 3.2.
}

concluded in Section 4 with an overview of the main results and implications, as well as recommendations for further research on this topic.

\section{Methodology}

\subsection{Experimental design}

The entire experiment included three parts, with the order of the first two parts varied randomly to control for order effects. This involved one part for measuring foresters' risk preferences by utilizing the task of Holt and Laury (2002) (HL task). In the second part, we elicited participants' discount rates by using the task of Coller and Williams (1999) (CW task). Finally, the third part consisted of a survey to gather specific socio-demographic and forestenterprise-related data, as well as the participants' personal perspective on forest management. ${ }^{3}$

The experiment focused on forestry decision makers, involving foresters working for private forest enterprises (mostly forest owners), communal forest managers, foresters working for state agencies and state-owned enterprises, as well as other forestry professionals, which were primarily forest service providers. The experiment was conducted online at the end of the year 2015. The feasibility and quality of the whole experiment were pretested. With the help of forest associations throughout Germany, about 2000 foresters were contacted by email and provided with the link to the experiment. ${ }^{4}$ In total, 142 individuals from the forestry sector participated, which corresponds to a final participation rate of $7 \% .^{5}$

\subsubsection{Holt and Laury task}

To measure the risk preferences of the participants, we followed Holt and Laury (2002), whose HL task is referred to as the "gold standard" of risk preference measurement methods (cf. Anderson et al. 2012). In the HL task, participants chose between two different lottery pairs: lottery A and lottery B. The original payout levels in the HL task were multiplied by 90 , as proposed by Holt and Laury (2002), in order provide sufficient incentives for

\footnotetext{
${ }^{3}$ The original experimental instructions were in German, but were translated into English and are presented as an Appendix to the online version of this article.

${ }^{4}$ Involved associations included the "Deutscher Forstverein e.V." and the "Arbeitsgemeinschaft Deutscher Waldbesitzer e.V.".

${ }^{5}$ Self-selection bias is often a crucial issue. Anderson et al. (2013) and Exadaktylos et al. (2013) analyzed potential self-selection bias with regard to preferences in laboratory experiments, however, they did not find differences in the responses between participants who were forced to participate and those who participated voluntarily.
} 
employed participants. In lottery A, the participants could potentially win EUR 180.00 with a probability of $p_{i}$ or EUR 144.00 with a probability of $1-p_{i}$. In lottery $\mathrm{B}$, the participants could potentially win EUR 346.50 with a probability of $p_{i}$ or EUR 9.00 with a probability of $1-p_{i}$ (Table 1$)$. In total, 10 choices $(i=1,2, \ldots, 10)$ had to be made. The monetary values remained constant for all lottery pairs, but probabilities varied. Starting with the first lottery pair, the probability $p_{1}$ was $10 \%$. Probabilities were then increased by $10 \%$ with each subsequent lottery pair until $p_{10}$ was equal to $100 \%$ (Table 1 ). The risk preference of the participants was determined by counting the number of times lottery A was selected, which refers to the so-called HL value. Risk neutral participants had an HL value of 4, since the expected value of lottery $\mathrm{B}$ was below the expected value of lottery A for the last time in row 4. For measuring the risk preference, we utilized the power utility function with constant relative risk aversion (CRRA) (cf. Holt and Laury 2002), from which we could derive CRRA values. The specific CRRA value of a participant was located within the range given for the row wherein lottery $\mathrm{B}$ was chosen for the first time.

To encourage thoughtful decision making, financial incentives were paid to randomly selected participants. We indicated to participants before conducting the HL task that the chance of being randomly selected was one out of 20. The amount of the financial incentive was determined by randomly selecting and carrying out one lottery pair according to the given probabilities and monetary amounts of the option selected by the participant.

\subsubsection{Coller and Williams task}

For eliciting the discount rate of foresters, we utilized the CW task structure based on Coller and Williams (1999). We used EUR 200 as the minimum potential financial incentive instead of USD 500, as proposed by Coller and Williams (1999), since this corresponds most closely to average payouts of the risk-neutral to slightly risk-averse decision makers in the HL task. For the elicitation of the discount rate, participants were confronted with a payout table as presented in Table 2. Participants chose in eleven rows between option A and option B. Option A offered a payout of EUR 200.00 in one month's time after the completion of the experiment, and option B offered the payment in seven months' time of the monetary amount of option A compounded quarterly by the given annual interest rate. The quarterly compounding corresponds to common banking practices (cf. Andersen et al. 2008). In total, 11 choices $(k=1,2, \ldots, 11)$ had to be made, where the annual interest rate was $0 \%$ in row 1 and increased by $1.5 \%$ with every subsequent row until it reached $15 \%$ in row 11 . The row in which the participant switched for the first time from option A to option B was depicted as the $\mathrm{CW}$ value and was used as the upper bound for deriving the range of potential discount rates $(\delta)$ under the assumption of risk neutrality in accordance with Coller and Williams (1999) and Andersen et al. (2008). The lower bound was defined by the previous decision situation, since indifference between the higher but later payment and the lower but earlier payment occurred between these two decision situations. For participants who
Table 1 Holt and Laury (HL) task according to Holt and Laury (2002)

\begin{tabular}{|c|c|c|c|c|c|c|c|}
\hline \multirow[t]{3}{*}{ Row } & \multicolumn{2}{|c|}{$\begin{array}{l}\text { Lottery A } \\
\text { Chance of } \\
\text { gaining }\end{array}$} & \multirow[t]{3}{*}{$\begin{array}{l}\text { Please choose one } \\
\text { lottery in each row }\end{array}$} & \multicolumn{2}{|c|}{$\begin{array}{l}\text { Lottery B } \\
\text { Chance of } \\
\text { gaining }\end{array}$} & \multirow[t]{3}{*}{$\begin{array}{l}\text { Difference between } \\
\text { the expected values } \\
(E U R)^{\mathrm{a}, \mathrm{b}}\end{array}$} & \multirow[t]{3}{*}{$\begin{array}{l}\text { Range of constant } \\
\text { relative risk aversion } \\
\text { if switching in this row }\end{array}$} \\
\hline & EUR & EUR & & EUR & EUR & & \\
\hline & 180.00 & 144.00 & & 346.50 & 9.00 & & \\
\hline 1 & $10 \%$ & $90 \%$ & $\mathrm{~A} \square \square \mathrm{B}$ & $10 \%$ & $90 \%$ & 104.85 & $-\infty \leq r<-1.71$ \\
\hline 2 & $20 \%$ & $80 \%$ & $\mathrm{~A} \square \square \mathrm{B}$ & $20 \%$ & $80 \%$ & 74.70 & $-1.71 \leq r<-0.95$ \\
\hline 3 & $30 \%$ & $70 \%$ & $\mathrm{~A} \square \square \mathrm{B}$ & $30 \%$ & $70 \%$ & 44.55 & $-0.95 \leq r<-0.49$ \\
\hline 4 & $40 \%$ & $60 \%$ & $\mathrm{~A} \square \square \mathrm{B}$ & $40 \%$ & $60 \%$ & 14.4 & $-0.49 \leq r<-0.15$ \\
\hline 5 & $50 \%$ & $50 \%$ & $\mathrm{~A} \square \square \mathrm{B}$ & $50 \%$ & $50 \%$ & -15.75 & $-0.15 \leq r<0.14$ \\
\hline 6 & $60 \%$ & $40 \%$ & $\mathrm{~A} \square \square \mathrm{B}$ & $60 \%$ & $40 \%$ & -45.90 & $0.14 \leq r<0.41$ \\
\hline 7 & $70 \%$ & $30 \%$ & $\mathrm{~A} \square \square \mathrm{B}$ & $70 \%$ & $30 \%$ & -76.05 & $0.41 \leq r<0.68$ \\
\hline 8 & $80 \%$ & $20 \%$ & $\mathrm{~A} \square \square \mathrm{B}$ & $80 \%$ & $20 \%$ & -106.20 & $0.68 \leq r<0.97$ \\
\hline 9 & $90 \%$ & $10 \%$ & $\mathrm{~A} \square \square \mathrm{B}$ & $90 \%$ & $10 \%$ & -136.35 & $0.97 \leq r<1.37$ \\
\hline 10 & $100 \%$ & $0 \%$ & $\mathrm{~A} \square \square \mathrm{B}$ & $100 \%$ & $0 \%$ & -166.50 & $1.37 \leq r \leq \infty$ \\
\hline
\end{tabular}

${ }^{a}$ Column is not shown to participants

${ }^{\mathrm{b}}$ The expected value is the expected value of lottery A minus the expected value of lottery B

${ }^{\mathrm{c}}$ A power utility function in the form $U(x)=\frac{x^{(1-r)}}{1-r}$ is assumed for the calculation 
Table 2 Coller and Williams (CW) task structure according to Coller and Williams (1999)

\begin{tabular}{|c|c|c|c|c|c|c|}
\hline Row & $\begin{array}{l}\text { Payment } \\
\text { option A } \\
\text { Payment in } \\
1 \text { month }\end{array}$ & $\begin{array}{l}\text { Please } \\
\text { choose } \\
\text { one } \\
\text { payment } \\
\text { option in } \\
\text { each row }\end{array}$ & $\begin{array}{l}\text { Payment } \\
\text { option B } \\
\text { Payment in } \\
7 \text { month }\end{array}$ & $\begin{array}{l}\text { Annual } \\
\text { interest } \\
\text { rate }\end{array}$ & $\begin{array}{l}\text { Annual } \\
\text { effective } \\
\text { interest } \\
\text { rate }^{\mathrm{a}}\end{array}$ & $\begin{array}{l}\text { Range of discount } \\
\text { rates if switching } \\
\text { in this row }{ }^{a}, b\end{array}$ \\
\hline 1 & EUR 200.00 & $\mathrm{~A} \square \square \mathrm{B}$ & EUR 200.00 & $0.0 \%$ & $0.00 \%$ & $-\infty<\delta \leq 0.00$ \\
\hline 2 & EUR 200.00 & $\mathrm{~A} \square \square \mathrm{B}$ & EUR 201.50 & $1.5 \%$ & $1.51 \%$ & $0.00<\delta \leq 1.51$ \\
\hline 3 & EUR 200.00 & $\mathrm{~A} \square \square \mathrm{B}$ & EUR 203.01 & $3.0 \%$ & $3.03 \%$ & $1.51<\delta \leq 3.03$ \\
\hline 4 & EUR 200.00 & $\mathrm{~A} \square \square \mathrm{B}$ & EUR 204.53 & $4.5 \%$ & $4.58 \%$ & $3.03<\delta \leq 4.58$ \\
\hline 5 & EUR 200.00 & $\mathrm{~A} \square \square \mathrm{B}$ & EUR 206.05 & $6.0 \%$ & $6.14 \%$ & $4.58<\delta \leq 6.14$ \\
\hline 6 & EUR 200.00 & $\mathrm{~A} \square \square \mathrm{B}$ & EUR 207.57 & $7.5 \%$ & $7.71 \%$ & $6.14<\delta \leq 7.71$ \\
\hline 7 & EUR 200.00 & $\mathrm{~A} \square \square \mathrm{B}$ & EUR 209.10 & $9.0 \%$ & $9.31 \%$ & $7.71<\delta \leq 9.31$ \\
\hline 8 & EUR 200.00 & $\mathrm{~A} \square \square \mathrm{B}$ & EUR 210.64 & $10.5 \%$ & $10.92 \%$ & $9.31<\delta \leq 10.92$ \\
\hline 9 & EUR 200.00 & $\mathrm{~A} \square \square \mathrm{B}$ & EUR 212.18 & $12.0 \%$ & $12.55 \%$ & $10.92<\delta \leq 12.55$ \\
\hline 10 & EUR 200.00 & $\mathrm{~A} \square \square \mathrm{B}$ & EUR 213.73 & $13.5 \%$ & $14.20 \%$ & $12.55<\delta \leq 14.20$ \\
\hline 11 & EUR 200.00 & $\mathrm{~A} \square \square \mathrm{B}$ & EUR 215.28 & $15.0 \%$ & $15.87 \%$ & $14.20<\delta \leq 15.87$ \\
\hline
\end{tabular}

${ }^{a}$ The annual effective interest rate is compounded quarterly

${ }^{\mathrm{b}}$ Column is not shown to participants chose option B already in the first row, the individual discount rate was lower than $0 \%$, and for participants who chose option A in each row, the individual discount rate was higher than $15.87 \%$.

The payout of option A was delayed by one month's time for three reasons. Firstly, the transaction of money takes some time, which makes it nearly impossible to provide the payout on exactly the same day the experiment is conducted. Secondly, although, we assured a risk-free payout, an instantaneous payout may be perceived as less risky. By delaying both payouts, the risk is perceived more equally (Andersen et al. 2008; Anderson and Stafford 2009). Thirdly, most decision makers have a high present bias, meaning that they have a high preference for an immediate payout in comparison to a delayed payout, which results in extremely high discount rates due to quasi-hyperbolicdiscounting. By offering two defined future payout times, the choice was more rational (Frederick et al. 2002).

Financial incentives were paid to randomly selected participants, with a one in 20 chance to win. The amount of the financial incentive was determined by randomly selecting one row in the $\mathrm{CW}$ task. The time of the payout was determined by the choice and took place as indicated in the experiment (calendar sheets in the $\mathrm{CW}$ task, cf. Appendix A).

\subsubsection{Structure of the survey}

The survey consisted of questions regarding the participants' socio-demographic data and information about the forest enterprise where the participants work, as well as questions regarding the participants' perception of forest management (see English translations of the questions in the Appendix A).

Socio-demographic data included age, education (converted to years of education, in accordance with OECD 1999), as well as questions with binary responses, such as whether they have children and their gender. Forestenterprise-related data was gathered by asking for the size of forestland they manage and the forest ownership structure. Additionally, one question was related to participants' perspective regarding investments in the forest enterprise, in order to control for economic motives.

\subsection{Analysis of risk and time preferences}

For the analysis of risk and time preferences, we followed the approach of Andersen et al. (2008). This approach involves a maximum likelihood estimation (MLE) for analyzing risk and time preferences simultaneously. The joint estimation of risk and time preferences has the great advantage that the measured discount rate can be corrected by the risk preference. Andersen et al. (2008) found significantly lower discount rates when they were corrected for the influence of the risk preference. This approach was tested by, e.g., Andreoni and Sprenger (2012) with various experimental settings. They found the estimations to be consistent with expected utility theory and the discounted utility model, as long as the time preference task does not involve certain and uncertain options simultaneously. 


\subsubsection{Elicitation of risk preferences}

For the estimation of the risk preferences in the MLE, we assumed a power utility function with CRRA (cf. Harrison and Rutström 2008; Holt and Laury 2002). The earnings from the experiment were assumed to be in addition to background levels of consumption. Background consumption $\omega$ of participants represented the personal average daily consumption of non-durable goods in Germany, which is equal to EUR $12.53 .^{6}$ This value is derived from the Federal Statistical Office of Germany (2013a) and was adjusted by the inflation rate to real values at the time of the experiment (2015). Following Andersen et al. (2008) and Frederick et al. (2002, p. 380), we assumed that the experimental earnings were perceived as additional income which was consumed in one day. In the situation, where the consumption of the earnings from the experiment is spread over several days, the marginal utility of the extra income increases. This implies that measured time preference may include some effects of diminishing marginal utility. ${ }^{7}$ We therefore added $\omega$ to the utility function $U(x+\omega)$ (Andersen et al. 2008) with the CRRA value $r: 8$

$U(x+\omega)=\frac{(x+\omega)^{(1-r)}}{1-r}$

By applying the MLE, we equated the utility of lottery A and lottery B through the adaption of $r$ (Andersen et al. 2008). Therefore, we first calculated the expected utility $(E U)$ in each decision situation $i$ of lottery $A$ and lottery $B$ of the HL task. Each lottery pair consisted of a lower $(l)$ and an upper $(u)$ value, and the respective probability $\left(p_{i}\right)$ in the HL task (Table 1):

$E U_{A i}=p_{i} \cdot U\left(x_{A u}+\omega\right)+\left(1-p_{i}\right) \cdot U\left(x_{A l}+\omega\right)$

The calculation of the expected utility of lottery B was similar to Eq. 2. In order to allow for some randomness in participants' choices, we incorporated the noise parameter $\mu$, which is specified as the Luce error term, as used by e.g., Andersen et al. (2008) and Harrison and Rutström (2008):

$\nabla E U=\frac{E U_{B}^{1 / \mu}}{E U_{B}^{1 / \mu}+E U_{A}^{1 / \mu}}$

\footnotetext{
${ }^{6}$ Similar results are achieved, when using, for instance, total daily average consumption (EUR 40.90).

${ }^{7}$ Effects of marginal utility are found to be of very low influence by varying $\omega$ and of some influence by varying the time of consuming the winning (cf. Andersen et al. 2008). This is furthermore supported by the neurological study of Kable and Glimcher (2010), who found very low influence of diminishing marginal utility on discounting behavior. Still, diminishing marginal utility cannot be fully excluded, which is why elicited discount rates must be interpreted accordingly.

${ }^{8}$ If $r=1$, the natural logarithm of 1 is used instead (Holt and Laury 2002).
}

As $\mu$ got larger, the choice became more random, whereas $\mu \rightarrow 0$ implied a deterministic expected utility theory model. In order to derive the CRRA value $r$, we assumed that both lottery pairs in the HL task led to the same utility when $r$ was correctly specified. Therefore, we maximized the fit by minimizing the difference between the choice of lottery A $\left(y_{i}=1\right)$ and lottery B $\left(y_{i}=0\right)$ :

$$
\begin{aligned}
\ln L^{E U}(r, \mu ; y, \omega, \mathbf{X})= & \sum_{i}\left(\left(\ln (\nabla E U) \mid y_{i}=1\right)\right. \\
& \left.+\left(\ln (1-(\nabla E U)) \mid y_{i}=0\right)\right)
\end{aligned}
$$

In Eq. 4, $\mathbf{X}$ represented participants' socio-demographic and forest-enterprise-related parameters.

\subsubsection{Elicitation of time preferences}

For eliciting time preferences, we followed the discounted utility model, where we assumed an exponential functional form. It is important to note that there is an ongoing discussion, as to which functional form best describes time preferences (described by e.g., Hepburn et al. 2010; Price 2011). For example, the concept of a hyperbolic functional form implies declining discount rates over time, which does not follow the axioms of rationality. We decided for the exponential functional form, since it is also applied in typical forestry investment profitability criteria, forestry decision makers are exposed to Gerst (2015).

The methodological approach for the estimation of discount rates is very similar to the approach for risk preferences. If we first assumed a risk-neutral decision maker, the discount rate could be elicited by equating the present value (PV) of option A and option B through the adjustment of the discount rate $\delta$. Therefore, we first calculated the $P V$ for option A:

$$
P V_{A}=(1+\delta)^{-\tau} \cdot\left(\omega+M_{A}\right)+(1+\delta)^{-t} \cdot \omega
$$

Thereby, $\tau$ was the 1-month front-end-delay of the payout of option $\mathrm{A}\left(M_{A}\right)$, including the consumption of $\omega$, whereas $t$ represented seven months' time, when the participant consumed only $\omega$. Accordingly to Eq. 5, $P V_{B}$ could be calculated where only $\omega$ was consumed in one month's time, but in seven months' time, the payout of option B $\left(M_{B}\right)$ as well as $\omega$ was consumed. $M_{A}$ and $M_{B}$ were shown and communicated to participants as nominal values and this is also how we expected participants to interpret them. In order to estimate the time preference of participants on the basis of real values, $M_{A}$ and $M_{B}$ were adjusted by the inflation rate to real values in the subsequent data analysis.

$P V_{B}=(1+\delta)^{-\tau} \cdot \omega+(1+\delta)^{-t} \cdot\left(\omega+M_{B}\right)$ 
In these specifications of the PV, it was again assumed that the experimental payout from the $\mathrm{CW}$ task was consumed in 1 day.

In order to integrate the CRRA value in the time preference functions (5 and 6), we used the estimated CRRA value $r$ from Eq. 4, and applied it in the $P V$ calculations for option $\mathrm{A}$ and $\mathrm{B}$ :

$$
\begin{aligned}
& P V_{A}=(1+\delta)^{-\tau} \cdot\left(\omega+M_{A}\right)^{1-r}+(1+\delta)^{-t} \cdot \omega^{1-r} \\
& P V_{B}=(1+\delta)^{-\tau} \cdot \omega^{1-r}+(1+\delta)^{-t} \cdot\left(\omega+M_{B}\right)^{1-r}
\end{aligned}
$$

We included a separate noise parameter ( $v$ ) for the estimation of $\delta$ in the time preference task, since the HL task and the CW task were regarded as cognitively different (Andersen et al. 2008):

$\nabla P V=\frac{P V_{B}^{1 / \mu}}{P V_{B}^{1 / \mu}+P V_{A}^{1 / \mu}}$

In order to derive the discount rate (DR) for expressing the time preference, $\delta$ was varied until the individual expected utility of both options was equal. For the estimation of $r$, we therefore maximized the fit by minimizing the difference between individually preferred option $\mathrm{A}\left(y_{k}=1\right)$ or option $\mathrm{B}\left(y_{k}=0\right)$ :

$$
\begin{array}{r}
\ln L^{D R}(r, \delta, \mu, v ; y, \omega, \mathbf{X}) \sum_{k}\left(\left(\ln (\nabla P V) \mid y_{k}=1\right)\right. \\
\left.+\left(\ln (1-(\nabla P V)) \mid y_{k}=0\right)\right)
\end{array}
$$

The joint MLE of the risk preference and the time preference can be expressed as:

$\ln L(r, \delta, \mu, v ; y, \omega, \mathbf{X})=\ln L^{E U}+\ln L^{D R}$

Since we expected participants to have individual preferences, regression results were clustered for each participant. We thereby allowed for correlation of choices by the individual participants, which resulted in adjusted standard errors (implemented by the option cluster in STATA 12.1).

\subsection{Data Availability}

The data are not publicly available due to them containing information that could compromise research participant privacy/consent. Anonymized data are however available

\begin{tabular}{|c|c|c|}
\hline & Mean & Standard deviation \\
\hline \multicolumn{3}{|l|}{ Socio-demographic characteristics: } \\
\hline Female participants $(\%)^{\mathrm{a}}$ & 11.3 & - \\
\hline Participants' age (years) & 52.2 & 14.8 \\
\hline Participants with children $(\%)^{\mathrm{a}}$ & 74.6 & - \\
\hline Years of education (years) & 16.3 & 2.8 \\
\hline \multicolumn{3}{|l|}{ Forest enterprise / agency-related characteristics: } \\
\hline State-owned forest enterprise $(\%)$ & 21.8 & - \\
\hline Communal forest enterprise $(\%)^{b}$ & 8.5 & - \\
\hline Private forest enterprise $(\%)$ & 55.6 & - \\
\hline Other forestry professionals $(\%)$ & 14.1 & - \\
\hline Size of forestland (ha) & $9,715.1$ & $43,426.6$ \\
\hline \multicolumn{3}{|l|}{ Goals of the hypothetical private forest enterprise ${ }^{c}$ : } \\
\hline Profit-maximization $(\%)$ & 47.1 & 27.2 \\
\hline Providing financial security $(\%)$ & 36.9 & 22.4 \\
\hline Other goals, e.g., providing ecological or social services (\%) & 16.0 & 20.1 \\
\hline \multicolumn{3}{|l|}{ Choices in the experiment: } \\
\hline Holt and Laury value (0 to 10$)^{\mathrm{d}, \mathrm{e}}$ & 5.7 & 2.4 \\
\hline Coller and Williams value $(1 \text { to } 12)^{\mathrm{f}}$ & 6.6 & 3.6 \\
\hline
\end{tabular}
from the corresponding author upon reasonable request.
Table 3 Descriptive statistics of participants $(\mathrm{N}=142)$
${ }^{\text {a }}$ Variable is binary coded

${ }^{\mathrm{b}}$ Communal forest enterprises are mostly owned by communities and religious institutions

${ }^{c}$ Participants stated the relative importance of various goals for their private forest enterprise

${ }^{\mathrm{d}} \mathrm{HL}$ task: values of $0-3$ : risk-seeking, value of 4: risk-neutral, values of 5-10: risk-averse

${ }^{\mathrm{e}}$ Inconsistent lottery choices were made by $18 \%$ of participants. Respective participants were included by counting the number of times lottery A was selected

${ }^{\mathrm{f}}$ Inconsistent choices were made by $10 \%$ of participants. Respective participants are not included in the calculation of the mean 
Table 4 Estimation of the constant relative risk aversion (CRRA) coefficient $(\mathrm{N}=142)$

\begin{tabular}{lllllll}
\hline Variable & Coefficient & Standard error & $p$-value & \multicolumn{2}{l}{$95 \%$ confidence interval } & \\
\hline CRRA value $r$ & 0.584 & 0.105 & $<0.001$ & 0.378 & 0.790 & *** \\
Noise parameter $\mu$ & 0.220 & 0.047 & $<0.001$ & 0.127 & 0.313 & *** \\
\hline
\end{tabular}

$. p<0.1, * p<0.05, * * p<0.01, * * * p<0.001$

\section{Results and discussion}

\subsection{Descriptive statistics}

The experiment included 142 German foresters. In Table 3, the descriptive statistics of the sample are summarized, including their socio-demographic and forest-enterpriserelated variables.

The proportion of female participants as well as the participants' ages are comparable to the actual population of German foresters (FAO 2006; Federal Statistical Office of Germany 2013b). However, the average years of education is relatively high (18 is equal to a university degree). This might be partly explained by the fact that we focused on participants who are responsible for forest management. It may also be due to initiating contact via email and conducting the experiment online. Online experiments reveal great advantages, such as reaching many potential participants easily (Granello and Wheaton 2004). However, access to the internet and willingness to participate in an online experiment is, perhaps, related to level of education to some extent (Granello and Wheaton 2004). Therefore, results should be interpreted as representing better-educated foresters, who are typically the leading decision makers in public and larger private forest enterprises.

Based on the mean HL value (number of times lottery A is selected), the mean CRRA value ranges between 0.14 and 0.68 . Thus, the sample can be described as slightly risk-averse to risk-averse. The $\mathrm{CW}$ value (row in which participant first switches to option B) reveals a mean discount rate in the range of 6.14 to $7.71 \%$ p.a. Inconsistent lottery choices were made by $18 \%$ of participants in the HL task and $10 \%$ in the CW task, meaning that they chose option A, then switched to option B, and later switched back to option A, for example. In the MLE, inconsistent choices do not constitute any hindrance. For the descriptive statistics, participants with inconsistent choices in the HL task are included by counting the number of times they selected lottery A (Holt and Laury 2002). Inconsistent choices in the $\mathrm{CW}$ task are not included in the descriptive statistics.

\subsection{Risk and time preferences}

The observed risk preferences estimated by the MLE (Table 4) are comparable to the results of Musshoff and Maart-Noelck (2014), but exhibit less risk-averse behavior than was found by Brunette et al. (2014). It is important to note that the studies differed with regard to the experimental approaches. The HL task was also used by Musshoff and Maart-Noelck (2014), whereas Brunette et al. (2014) conducted a task according to Eckel and Grossman. Several studies comparing these approaches found different mean values but correlating results nonetheless (Sauter et al. 2016).

From the MLE of the choices in the CW task, we estimate the discount rate $\delta$ to be $7.3 \%$ (Table 5). The estimation of $\delta$ in this analysis involves both the time preference and the risk preference. The confidence interval of our estimated $\delta$ includes the discount rate for five year rotations $(8 \%)$ elicited by Bullard and Gunter (2002) with a poll in the USA. There are also non-significant differences between the discount rate found by the present study and the applied interest rate in forest management in the southern USA (Brukas et al. 2001, p. 145) (7-8\%). However, our estimated discount rate is much lower in comparison with the results of Kronrad and de Steiguer (1983) (15\%) and Prestemon and Wear (2000) (18\%) for non-industrial private forest owners.

For the elicitation of the time preference discount rate, we jointly estimate the risk and time preference (Table 6). As a result, the MLE exhibits a $\delta$ of $4.1 \%$, which is
Table 5 Estimation of the discount rate $(\mathrm{N}=142)$

\begin{tabular}{lllllll}
\hline Variable & Coefficient & Standard error & $p$-value & \multicolumn{2}{l}{$95 \%$ confidence interval } & \\
\hline Discount rate $\delta$ & 0.073 & 0.007 & $<0.001$ & 0.061 & 0.086 & $* * *$ \\
Noise parameter $v$ & 0.021 & 0.002 & $<0.001$ & 0.018 & 0.025 & $* * *$ \\
\hline
\end{tabular}

. $p<0.1, * p<0.05, * * p<0.01, * * * p<0.001$ 
Table 6 Joint estimation of the constant relative risk aversion (CRRA) coefficient and the discount rate $(\mathrm{N}=142)$

\begin{tabular}{lllllll}
\hline Variable & Coefficient & Standard error & $p$-value & \multicolumn{2}{l}{$95 \%$ confidence interval } & \\
\hline CRRA value $r$ & 0.584 & 0.106 & $<0.001$ & 0.377 & 0.791 & $* * *$ \\
Discount rate $\delta$ & 0.041 & 0.006 & $<0.001$ & 0.030 & 0.052 & $* * *$ \\
Noise parameter $\mu$ & 0.220 & 0.048 & $<0.001$ & 0.126 & 0.313 & $* * *$ \\
Noise parameter $v$ & 0.007 & 0.002 & 0.002 & 0.003 & 0.012 & $* *$ \\
\hline
\end{tabular}

. $p<0.1, * p<0.05, * * p<0.01, * * * p<0.001$

significantly lower (Wald test: $p<0.001$ ) than the $\delta$ of the previous estimation. This distinct difference demonstrates the importance of the corrected discount rate that accounts for the influence of risk preference (cf. Anderhub et al. 2001). The elicited $\delta$ is in line with the assumed $4 \%$ discount rate historically used in European forestry (Price 2014, p. 56). However, our $\delta$ is higher than the discount rate of $2.6 \%$ elicited by Atmadja and Sills (2013, p. 112) for foresters in the USA. Furthermore, our $\delta$ is clearly higher than the typical discount rate applied as the internal rate of return in German forestry, which was determined to be about $0 \%$ by Brukas et al. (2001). Möhring (2014) calculated a discount rate of $1.1 \%$, which is the profitability of forest land investments derived from accounting data of surveyed forest enterprises in north-western Germany. Gerst (2015, p. 99) calculated discount rates on the basis of forest inventory data in Germany, leading to a discount rate of $2.5 \%$ on average.

As a consequence, most foresters should not be willing to invest in forestry, since their time preferences are usually higher than common internal rates of return in German forestry. Reasons why they might still invest in forest assets are discussed in the following arguments:

- Some advocates in forest and environmental economics favor the theory of highest mean annual net revenue over the more established land rent theory, implying a marginal interest rate (which is seen as equal to the discount rate in this context) of 0\% (Brukas et al. 2001).

- Other advocates argue to correct net present values by taking into account social opportunity costs and positive externalities of forests, which is especially relevant for older stands. The derived internal rates of return are higher and are referred to as the social discount rate (described by Brukas et al. 2001; Gerst 2015, p. 102). This argument is particularly relevant for public forest owners, however, has rarely been found to be applied in forest management (Brukas et al. 2001).

- Forests are often expected to be managed with the aim of passing high forest values on to the next generation (Bullard and Gunter 2002). In this context, discount rates play only a minor role. Coming from a more altruistic perspective, this argument also refers to intergenerational justice, which does not allow for discrimination against future generations' forest values and, thus, leaves no room for discounting (cf. Price 2014, p. 62).

- In comparison to other investment alternatives, forest assets provide more flexibility since the harvest can be deferred for some years after a certain age, usually without relevant timber quality losses. This is comparable to a savings account, however, requires stable timber prices (Möhring 2014). This flexibility, however, is not free of cost since it comes along with lower net present values due to delayed harvesting.

- In this analysis, we assumed an underlying exponential functional form of time preferences. However, to a certain extent individuals time preferences might be better described by an, e.g., hyperbolic functional form implying declining discount rates over time. This leads to very low discount rates of earnings in the far future, and is sometimes regarded as more "sustainable", although this leads to time inconsistent behavior (described by, e.g., Hepburn and Koundouri 2007; Hepburn et al. 2010).

Although, the question of the optimal specification of the functional form for individuals time preferences can potentially lead to some inaccuracy, we do not expect high deviations in this respect; Andersen et al. (2008) found that the variation in elicited time preferences by varying the functional form are of low magnitude, when risk attitudes are included in the estimation.

- In terms of an entire investment portfolio, forest assets are found to have a risk-reducing effect, ${ }^{9}$ which is why lower internal rates of return are accepted (e.g., Lundgren 2005). Forest assets themselves are diverse (including different tree species and forest products, such as various wood assortments and hunting) and, thus, have a comparably low risk level (Brukas et al. 2001, p. 145). Furthermore, a high hedging potential for

\footnotetext{
${ }^{9}$ To have risk reducing effects, which are measured by the beta value, it is required that forests revenues have non-positive correlations with other investments alternatives. For instance, Lundgren (2005) demonstrated a low negative beta of -0.03 for forest revenues in comparison to the general market development in Sweden. In other words, forest revenues development is uncoupled from the general market development.
} 
Table 7 Detailed model of the joint estimation of the constant relative risk aversion (CRRA) coefficient and the discount rate $(\mathrm{N}=142)$

\begin{tabular}{|c|c|c|c|c|}
\hline Variable & Coefficient & Standard error & $p$-value & \\
\hline \multicolumn{5}{|l|}{ CRRA value $r$} \\
\hline Constant & 0.202 & 0.279 & 0.468 & \\
\hline Female participant (yes: 1 ; no: 0 ) & -0.010 & 0.069 & 0.885 & \\
\hline Participants' age (years) & 0.005 & 0.002 & 0.022 & $*$ \\
\hline Participant having children (yes: 1 ; no: 0 ) & -0.068 & 0.085 & 0.431 & \\
\hline Educational years (years) & 0.011 & 0.009 & 0.214 & \\
\hline Communal forest enterprise (yes: 1 ; no: 0 ) & 0.050 & 0.127 & 0.691 & \\
\hline Private forest enterprise (yes: $1 ;$ no: 0 ) & 0.156 & 0.075 & 0.038 & $*$ \\
\hline Other forestry professionals (yes: 1 ; no: 0 ) & 0.054 & 0.084 & 0.519 & \\
\hline Size of forestland (ha) & $-3 e-8$ & $5 e-7$ & 0.951 & \\
\hline Providing financial security (\%) & 0.0003 & 0.001 & 0.788 & \\
\hline $\begin{array}{l}\text { Other goals, e.g., providing ecological or } \\
\text { social services }(\%)\end{array}$ & 0.001 & 0.002 & 0.378 & \\
\hline \multicolumn{5}{|l|}{ Discount rate $\delta$} \\
\hline Constant & 0.076 & 0.030 & 0.010 & $* *$ \\
\hline Female participant (yes: 1 ; no: 0 ) & -0.013 & 0.010 & 0.177 & \\
\hline Participant's age (years) & -0.001 & 0.0004 & 0.103 & \\
\hline Participant having children (yes: 1 ; no: 0 ) & -0.006 & 0.011 & 0.583 & \\
\hline Educational years (years) & 0.0005 & 0.001 & 0.641 & \\
\hline Communal forest enterprise (yes: 1 ; no: 0 ) & -0.016 & 0.010 & 0.117 & \\
\hline Private forest enterprise (yes: 1 ; no: 0 ) & -0.014 & 0.008 & 0.079 & - \\
\hline Other forestry professionals (yes: $1 ;$ no: 0 ) & -0.004 & 0.010 & 0.676 & \\
\hline Size of forestland (ha) & $-7 e-8$ & $7 e-8$ & 0.360 & \\
\hline Providing financial security (\%) & 0.0003 & 0.0002 & 0.029 & * \\
\hline $\begin{array}{l}\text { Other goals, e.g., providing ecological or } \\
\text { social services }(\%)\end{array}$ & 0.0002 & 0.0002 & 0.303 & \\
\hline Noise parameter $\mu$ (for $r$ ) & 0.149 & 0.045 & 0.001 & $* *$ \\
\hline Noise parameter $v($ for $\delta$ ) & 0.004 & 0.002 & 0.030 & $*$ \\
\hline
\end{tabular}

. $p<0.1, * p<0.05, * * p<0.01, * * * p<0.001$ inflation risks is attributed to forests investments (e.g., Hyytiäinen and Penttinen 2008).

In this study, we cannot control for all of these potentially influential factors. However, we can shed some light on the interaction of time and risk preference with socio-demographic and forest-enterprise-related parameters (Table 7).

With regard to socio-demographic parameters, we do not observe statistically significant differences $(p>0.1)$ in the $r$ and the $\delta$ between female and male participants. However, risk aversion increases significantly with age $(p=0.022)$, implying that older people are more riskaverse. ${ }^{10}$ In contrast, $\delta$ does not significantly differ with respect to participants' age $(p>0.1)$, which is in line with the results of Bullard and Gunter (2002) and Kronrad and de Steiguer (1983). Participants who have children do

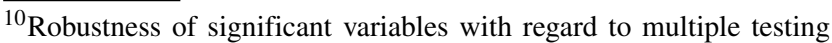
was supported by separate reduced models.
}

not have significantly different risk and time preferences than others $(p>0.1)$. Regarding $r$, this finding is in line with e.g., Harrison et al. (2007), however, with regard to $\delta$, it contradicts the results of Atmadja and Sills (2013) in the forestry context, who found that having children is correlated with an increased discount rate. In the present study, education is not of significant influence on $r$ and $\delta$ $(p>0.1)$, which is in line with the findings of Atmadja and Sills (2013), but contrasts the results of Harrison et al. (2007), who found that a higher education level leads to increased risk aversion. In this context, it is noteworthy that the sample in the present study is predominantly welleducated.

The analysis reveals that forest-enterprise-related parameters influence both $r$ and $\delta$. With regard to the ownership structure, foresters working for private forest enterprises have a higher $r$ in comparison to state-owned and communal forest enterprises, as well as other forestry professionals. Due to the fact that most participating foresters who work 
for private forest enterprises are self-employed, this finding is in line with Sauter et al. (2016) and Roe (2015). They found self-employed foresters and farmers to be more risk-averse than salaried foresters and farmers, respectively. The $\delta$ of foresters working for private forest enterprises is significantly lower $(p=0.079)$ which results in a $\delta$ of $3.7 \%$, obtained from a separate estimation on this subgroup whereas $\delta$ is $4.6 \%$ for the other participating foresters. This finding contradicts the results of Prestemon and Wear (2000), who found that non-industrial private forest owners have a higher discount rate than other forest owners in the USA. In Germany, Gerst (2015, p. 99) also found that private forest enterprises have a clearly higher discount rate $(2.5 \%)$ compared to state-owned forest enterprises and agencies (1.6\%). Moreover, in contrast to the present study, Gerst (2015, p. 99) found different discount rates between communal forest enterprises and state-owned forest enterprises and agencies. In this context, it is important to note that the present study elicited the discount rate with respect to time preference, whereas the discount rates in the studies of Prestemon and Wear (2000) and Gerst (2015) were observed from ex-post forest management decisions, implying time discounting and involving the influence of many more factors, such as the actual risk and risk preferences.

In line with the findings of Kronrad and de Steiguer (1983) as well as Bullard and Gunter (2002), we do not find the size of forestland to be significantly related to $r$ or $\delta(p>0.1)$. The goals of forest enterprises do not show significant influences on $r(p>0.1)$, however, putting a higher emphasis on the goal of liquidity preservation correlates with a significant increase of $\delta(p=0.029)$. This implies that participants who regard a forest as a way to deposit their money, much like a savings account, demand slightly higher internal rates of return than other participants.

In order to provide an overview of the spectrum of risk and time preferences, we utilize cumulative density plots (Fig. 1, the respective density plot is depicted in Appendix B). Thereby, we differentiate between foresters working for private forest enterprises and other foresters, since these groups are found to have deviating values for $r$ and $\delta$. Moreover, as Kant (1999) stated, in order to provide detailed information on time and risk preferences for forest management models and policy making, we should consider the groups separately. The cumulative density-plots allow policymakers to detect the percentile of decision makers covered by a certain policy measure (Botzen and van den Bergh 2014). When we focus on CRRA, most foresters have CRRA values roughly between -0.1 and 1.4 , with the main differences between foresters working for private forest enterprises and other foresters evident in the range of 0.7 to 1.4. Most participating foresters can be categorized as risk-neutral to highly risk-averse (cf. Holt and Laury 2002), with foresters working for private forest enterprises being more risk averse than other foresters. With regard to the time preference, discount rates mostly range between 0 and $7 \%$. Within this range, differences occur between foresters working for private forest enterprises and other participating foresters, who have higher discount rates on average. This implies that policy measures with aims such as increasing the provision of positive externalities from forestry, should consider the differences between foresters of the relevant ownership structure in order to ensure that the policy will cover the desired proportion of total forests. For
Fig. 1 Cumulative density plot of medium CRRA values and discount rates (in \%) from foresters who work for private forest enterprises $(\mathrm{N}=79)$ and foresters who do not work for private forest enterprises $(\mathrm{N}=63)$
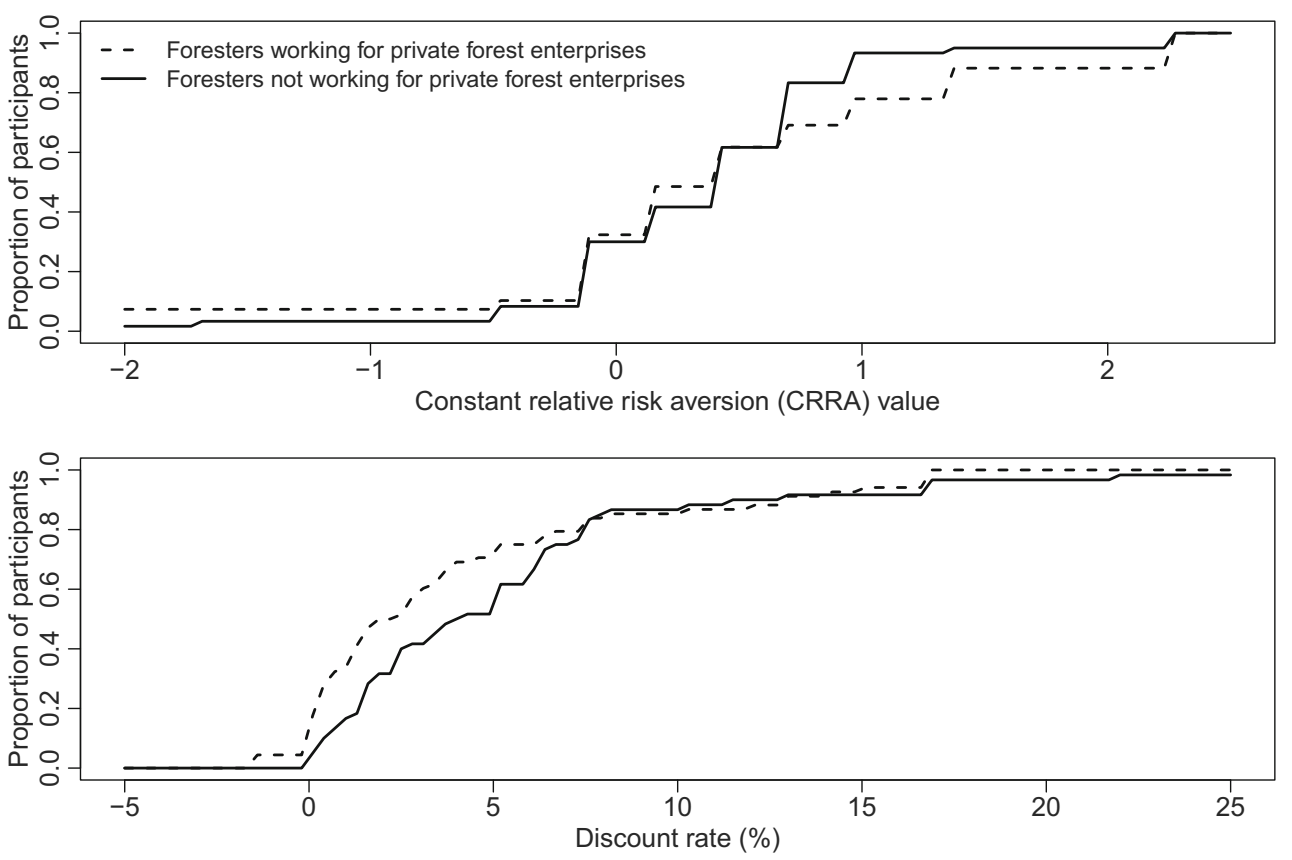
instance, this information could be relevant when designing policy measures to influence the proportion of foresters opting for natural regeneration versus replanting, which enables planning for future forest needs and adaption to climate change. In this context, Fig. 1 graphically provides evidence for the distribution of the risk preference and time preferences across foresters, which allows for more precisely targeted policy making.

\section{Conclusion}

Decision making in forestry is greatly affected by the risk and time preference of foresters. Forest management, which involves long rotations, requires both patience and acceptance of risk. Therefore, detailed knowledge regarding the risk and time preferences of forestry decision makers is of great importance for understanding their decision making behavior, especially in light of policy measures aiming to increase the provision of generation-spanning values and positive externalities. In order to analyze risk and time preferences, the present study examined these preferences jointly, which allows for a differentiated output. As a result, we arrive at two main conclusions:

(1) Results of the estimations reveal that firstly, the CRRA value for the group of foresters is 0.58 , meaning that they can be categorized as risk-averse (Holt and Laury 2002). The cumulative density plot of foresters risk preferences shows that most foresters have a CRRA value between -0.1 and 1.4. Secondly, foresters' time preferences result in a discount rate of $4.1 \%$, ranging mostly between 0 and $7 \%$. Thus, most foresters' time preferences are higher than typical internal rates of return in German forestry. These differences may be due to the potentially riskreducing effects of having forest assets in a portfolio as well as the additional amenity values of forest ownership. This conclusion is further underscored by the finding that foresters working for and, for the most part, owning a private forest enterprise, exhibit lower discount rates and higher CRRA values. This study demonstrates that both risk and time preferences differ widely between individual forestry decision makers. Thus, for the design of policy measures, policymakers should take into account the variety of risk and time preferences that exist among forestry decision makers. In order to encourage future positive externalities from forest management, tailored incentives should be provided (e.g., contractual conservation management agreements) on the basis of detailed distributions of foresters' risk and time preferences, as well as other factors. This conclusion is based on the assumption of constant discount rates (exponential discounting) with regard to time preferences. Time-inconsistent behavior with time-varying discount rates (hyperbolic discounting) may occur and highlights the need for further research on this topic.

(2) There are significant differences in the results when estimating time preferences directly versus jointly with the risk preference. Our findings thereby agree with the studies favoring joint estimation (e.g., Anderhub et al. 2001; Andersen et al. 2008; Coble and Lusk 2010). Therefore, when talking about discount rates in forestry, we support Price (2014, p. 63) in recommending that instead of general discount rates, discussions should refer separately to, e.g., risk preferences and time preferences, since risks differ by site and stand age, while risk and time preferences differ distinctly between decision makers. Thus, for the understanding of foresters' behavior, some of their decisions can be explained by risks and risk preferences, while others can be better explained by time preferences. As a consequence, decision support systems for forest management as well as forest economics models, should incorporate individual risk and time preferences separately.

Finally, it should be noted that the elicited risk and time preferences of the present study are not cast in stone, but may vary with regard to the influence of the experimental design (e.g., Hermann and Musshoff 2015). However, these results provide some useful information on actual individual risk and time preferences of foresters. Follow-up experiments should vary the experimental design in order to check for robustness and integrate further elements which may help to understand foresters' decision making, such as hyperbolic discounting (cf. Price 1993). Furthermore, it would be especially interesting to know how an experimental design utilizing a forestry framing influences discounting behavior. In addition, it would be helpful to compare risk and time preferences in an international context and between foresters following distinctly different management principles.

Acknowledgements The authors would like to thank Bernhard Möhring for constructive discussions and two anonymous referees and the editors for helpful comments and suggestions.

Funding We further gratefully acknowledge financial support from Deutsche Forschungsgemeinschaft (DFG).

\section{Compliance with Ethical Standards}

Conflict of interest The authors declare that they have no conflict of interest. 


\section{References}

Anderhub V, Guth W, Gneezy U, Sonsino D (2001) On the interaction of risk and time preferences: an experimental study. Ger Econ Rev 2(3):239-253

Andersen S, Harrison GW, Lau MI, Rutström EE (2008) Eliciting risk and time preferences. Econometrica 76(3):583-618

Anderson J, Burks SV, Carpenter J, Götte L, Maurer K, Nosenzo D, Potter R, Rocha K, Rustichini A (2013) Self-selection and variations in the laboratory measurement of other-regarding preferences across subject pools: evidence from one college student and two adult samples. Exp Econ 16(2):170-189

Anderson LR, Freeborn BA, Hulbert JP (2012) Risk aversion and tacit collusion in a bertrand duopoly experiment. Rev Ind Organ 40(1):37-50

Anderson LR, Stafford SL (2009) Individual decision-making experiments with risk and intertemporal choice. J Risk Uncertain 38(1):51-72

Andreoni J, Sprenger C (2012) Risk preferences are not time preferences. Am Econ Rev 102(7):3357-3376

Atmadja SS, Sills EO (2013) Forest management and landowners' discount rates in the Southern United States. In: Kant S (ed) PostFaustmann forest resource economics, sustainability, economics, and natural resources. Springer, Dordrecht, Netherlands, pp 91123

Binmore K (1999) Why experiment in economics? Econ J 109(453):16-24

Botzen WJW, van den Bergh JCJM (2014) Specifications of social welfare in economic studies of climate policy: overview of criteria and related policy insights. Environ Resour Econ 58(1):1-33

Brukas V, Jellesmark Thorsen B, Helles F, Tarp P (2001) Discount rate and harvest policy: implications for Baltic forestry. For Policy Econ 2(2):143-156

Brunette M, Foncel J, Kéré EN (2014) Attitude towards risk and production decision: an empirical analysis on French private forest owners. Centre d'études et de recherches internationales working paper no 2014-10, Montréal, France

Bullard S, Gunter JE (2002) Discount rates for nonindustrial private forest landowners in Mississippi: how high a hurdle? South J Appl For 26(1):26-31

Coble KH, Lusk JL (2010) At the nexus of risk and time preferences: an experimental investigation. J Risk Uncertain 41(1):67-79

Coller M, Williams MB (1999) Eliciting individual discount rates. Exp Econ 2(2):107-127

Domínguez G, Shannon M (2011) A wish, a fear and a complaint: understanding the (dis)engagement of forest owners in forest management. Eur J For Res 130(3):435-450

Duquette E, Higgins N, Horowitz J (2014) Inferring discount rates from time-preference experiments. Econ Lett 123(2):212215

Exadaktylos F, Espín AM, Branas-Garza P (2013) Experimental subjects are not different. Sci Rep (3):1213

Eyvindson K, Kangas A (2016) Integrating risk preferences in forest harvest scheduling. Ann For Sci 73(2):321-330

FAO (2006) Time for action: changing the gender situation in forestry: Report of the team of specialists on gender and forestry. Food and Agricultural Organization of the United Nations (FAO), Rome

Federal Statistical Office of Germany (2013a) Aufwendungen privater haushalte für den privaten konsum. https://www.destatis.de/DE/ Publikationen/Thematisch/EinkommenKonsumLebensbedingungen/ Konsumausgaben/EVS_AufwendungprivaterHaushalte.html
Federal Statistical Office of Germany (2013b) Erwerbstätigkeit in Deutschland - Ergebnisse des Zensus 2011. https://www.destatis.de/ DE/Publikationen/Wirtschaftstatistik/Zensus/Erwerbstaetigkeit2011_ 92014.html

Frederick S, Loewenstein G, O'donoghue T (2002) Time discounting and time preference: a critical review. J Econ Lit 40(2):351-401

Gerst JM (2015) Der Grenzzins als Entscheidungskriterium in der Forstwirtschaft: Methodisches Konzept und Empirische Evidenz, vol. 21 of Schriften zur Forst- und Umweltökonomie. Sauerländer Verlag, Bad Orb

Granello DH, Wheaton JE (2004) Online data collection: strategies for research. J Couns Dev 82(4):387-393

Harrison GW, Lau MI, Rutström EE (2007) Estimating risk attitudes in Denmark: a field experiment. Scand J Econ 109(2):341-368

Harrison GW, Rutström EE (2008) Risk aversion in the laboratory. In: Cox JC, Harrison GW (eds) Risk aversion in experiments, research in experimental economics, Emerald Group Publishing Limited. Bingley, Great Britain, pp 41-196

Hepburn C, Duncan S, Papachristodoulou A (2010) Behavioural economics, hyperbolic discounting and environmental policy. Environ Resour Econ 46(2):189-206

Hepburn CJ, Koundouri P (2007) Recent advances in discounting: implications for forest economics. J For Econ 13(2-3):169-189

Hermann D, Musshoff O (2015) Anchoring effects in experimental discount rate elicitation. Appl Econ Lett 23(14):1022-1025

Holt CA, Laury SK (2002) Risk aversion and incentive effects. Am Econ Rev 92(5):1644-1655

Hyytiäinen K, Penttinen M (2008) Applying portfolio optimisation to the harvesting decisions of non-industrial private forest owners. For Policy Econ 10(3): 151-160

Kable JW, Glimcher PW (2010) An 'as soon as possible' effect in human intertemporal decision making: behavioral evidence and neural mechanisms. J Neurophys 103(5):2513-2531

Kant S (1999) Endogenous rate of time preference, traditional communities, and sustainable forest management. J Soc Econ Dev 2(1):65-87

Kant S, Wang S, Deegen P, Hostettler M, von Detten R, Howard T, Laband D, Montgomery C, Robert N, Sekot W, Valatin G, Zhang D (2013) New frontiers of forest economics. For Policy Econ $35: 1-8$

Kronrad GD, de Steiguer JE (1983) Relationships between discount rates and investment lengths among nonindustrial private landowners: small woodlot r\&d program. Research Note Series (19)

Lundgren T (2005) Assessing the investment performance of swedish timberland: a capital asset pricing model approach. Land Econ 81(3):353-362

Möhring B (2014) Gibt es einen richtigen Zinssatz bei der forstlichen Wertermittlung? Wertermittlungsforum 32(2):72-78

Musshoff O, Maart-Noelck SC (2014) An experimental analysis of the behavior of forestry decision-makers - the example of timing in sales decisions. For Policy Econ 41:31-39

OECD (1999) Classifying educational programmes: manual for ISCED-97 implementation in OECD countries. Organisation for Economic Co-operation and Development (OECD) Publishing, Paris

Prestemon JP, Wear DN (2000) Linking harvest choices to timber supply. For Sci 46(3):377-389

Price C (1993) Time, discounting, and value. Blackwell, Oxford

Price C (2011) Optimal rotation with declining discount rate. J For Econ 17(3):307-318 
Price C (2014) Temporal aspects in forest economics. In: Kant S, Alavalapati JRR (eds) Handbook of forest resource economics, Earthscan from Routledge. London, Great Britain, pp 50-66

Roe BE (2015) The risk attitudes of U.S. farmers. Appl Econ Perspect Policy 37(4):553-574

Samuelson PA (1976) Economics of forestry in an evolving society. Econ Inq 14(4):466-492
Sauter P, Hermann D, Musshoff O (2016) Risk attitudes of farmers, foresters and students: an experimental multimethod comparison. In: Australian agricultural and resource economics society (ed.), AARES 2016 annual conference

Simonsen R (2013) Optimal regeneration method - planting vs. natural regeneration of scots pine in Northern Sweden. Silva Fennica 47(2):1-23 